\title{
Give me a break: Laughing with colleagues guards against ego depletion
}

\author{
Tabea Scheel
}

Fern Universitaet in Hagen

tabea.scheel@fernuni-hagen.de

\section{Daniel Putz}

Rhenish University of Applied Sciences Cologne

daniel.putz@rfh-koeln.de

\section{Chris Kurzawa}

Beuth University of Applied Sciences Berlin

chris.kurzava@googlemail.com

\begin{abstract}
Job demands, like time pressure, consume employees' limited resources, which need to be restored through recovery in order to maintain psychological well-being and work performance. Employees in high-strain jobs need to replenish their emotional resources throughout the work day. This can take place during breaks if employees are able to psychologically detach from the work demands. Given the stress-relieving functions of humour, we hypothesised that affiliative humour during breaks would attenuate affective impairments related to time pressure and would decrease negative emotional spillover from breaks to subsequent work. We conducted moderated mediation analyses with bootstrapping based on a cross-sectional sample of 170 employees working at four retail stores. Time pressure was positively related to affective irritation, which in turn was related to more spillover of negative (and less spillover of positive) mood from breaks to work. Laughing with colleagues during breaks moderated the link between time pressure and affective irritation, such that this relation became nonsignificant when the frequency of joint laughter during breaks increased. Hence, pleasurable social break activities appear to be important for within-workday recovery. Employers should encourage their employees to take their breaks consistently and to socialise with likable colleagues, especially during periods of high work load.
\end{abstract}

Keywords: break laughter, time pressure, affective irritation, mood spillover, ego depletion. 


\section{Introduction}

Job demands constantly consume employees' limited resources and jeopardise both their health and performance at work (De Jonge et al. 2012). However, employees can effectively restore their resources through recovery so that physical health, psychological well-being, and performance can be maintained at a high level (Sonnentag \& Zijlstra 2006). Detachment from work is important for replenishing resources and thus countering ego depletion (Muraven \& Baumeister, 2000). Various kinds of off-job recovery, such as end-of-day breaks (Sonnentag \& Bayer 2005), and vacations (Fritz \& Sonnentag 2006) help to effectively restore resources from one day to another. Yet, employees in high-strain jobs, for instance, service workers who engage in emotional labour while handling customers, regularly need to replenish their emotional resources before the work day is over. Breaks offer employees the opportunity to quickly recover their emotional resources during working hours (Trougakos \& Hideg 2009), but due to the limited amount of time and the reduced opportunity to emotionally and physically detach from work, the recovery effect will depend on the kinds of activities employees engage in during their breaks (De Jonge et al. 2012). Humour is an inherent part of human interactions at work (Robert \& Wilbanks 2012; Wood et al. 2011) and is related to employees' stress, well-being, performance, job satisfaction, and withdrawal (Mesmer-Magnus et al. 2012). Given the stress-relieving and social functions of humour and laughter (Berk et al. 2001; Martin et al. 1993; Nezu et al. 1988), we postulate that not only time spent with colleagues but also the frequency of laughter shared with them should add to the ability to detach emotionally from work and to recover emotional resources.

Using a sample of retail employees, we aimed to show that enjoyable break activities would be favourable for countering ego depletion. Specifically, laughter should be beneficial over and above socialising. Laughing with colleagues during breaks should attenuate the relation between time pressure and affective well-being, which in turn should be related to emotional spillover from break to work. Our study highlights the importance of engaging in pleasurable social activities during breaks for recovery during the work day.

To our knowledge, no quantitative studies about the role of humour during breaks have been conducted yet. Whereas Trougakos et al. (2014) focused on socialising during lunch breaks, they did not specify with whom the break was spent. By contrast, we included breaks in general and specifically targeted socialisation with colleagues as they provide an important source of social support. Humour and laughter may add to the explanation of why and how socialising during breaks counters ego depletion.

\section{Theory}

\subsection{The daily hassle: Job demands challenge self-regulation through resource depletion}

People experience work as exhausting, and hence, subjective well-being and high-quality work results can be maintained only for a limited amount of time. Ego Depletion Theory (EDT) (Muraven \& Baumeister 2000) accounts for this by explaining that people have a limited store of energy that they apply toward regulating their behaviour at any time. Whenever a person engages in self-regulating activities (e.g., focusing attention, monitoring actions, or regulating emotions), a certain amount of energy is depleted, hence reducing the amount of resources available to regulate behaviour afterwards. This decrease in regulatory resources is accompanied by impairments in subjective well-being, such as feelings of fatigue, strain, or affective irritation, all of which require additional regulatory effort in order 
to be coped with. If resource depletion continues without any opportunity to restore energy, impairments to the ability to effectively regulate one's actions become apparent with increasing frequency and intensity over time.

Thus, ego depletion challenges the self-regulatory process in a two-fold way: Whereas dealing with challenging demands constantly reduces the amount of self-regulatory resources that are available, the constant threat of sudden failures in self-regulation increasingly affects well-being, thereby consuming growing amounts of self-regulatory resources itself. Ego depletion is characterised by an increasing need to constantly decrease resources, finally resulting in apparent failures in self-regulation, such as bad planning, spurious actions, or the inability to cope with emotionally challenging experiences. Stated briefly, EDT suggests that ongoing job demands cause self-regulatory failures at work through the process of ego depletion.

\subsection{When emotions count: Time pressure, affective irritation, and emotional spillover in emotion work}

This general EDT framework can be applied to certain jobs or work tasks in order to better explain and to effectively influence resource depletion processes in practice. For instance, many jobs entail certain kinds of "people work" (e.g., serving customers in retail or catering, consulting clients in financial services, or selling products to corporate clients in sales and distribution), which require emotion work, that is, "emotional regulation [...] in the display of organisationally desired emotions" (Zapf et al. 1999: 371). This involves ongoing selfregulatory activities, such as understanding a client's emotional situation, activating the relevant social rules that determine which emotions should be suppressed or evoked in the given situation, perceiving one's own actual emotional state, and coping with the demand to suppress one's actual feelings or to express diverging emotions (Zapf et al. 1999; Hochschild 1979).

Most employees who do emotion work will gather an adequate amount of regulatory resources and develop effective strategies for dealing with such regulatory demands during a regular work day through vocational training and work experience. As long as their regulatory resources are high, they will be able to effectively regulate their emotions according to the current situational demands without lasting effects on their overall emotional well-being. However, if the current situation suddenly requires additional resources, ego depletion is likely to result. For instance, emotion work is often characterised by subjective time pressure, as customer requests can occur suddenly at any time during operating hours and are usually expected to be tended to immediately regardless of whether the responsible employee has other work obligations or not. Thus, "the sense that one's duties and responsibilities exceed one's ability to complete them in the time available" (Kleiner 2014: 108 ) is likely to occur and may further accelerate resource depletion, jeopardising affective well-being and effective self-regulation. In fact, research shows that time pressure at work is related to work stress (2 years later, US panel; Kleiner 2014), is detrimental to day-level work engagement if job control is low (Kühnel et al. 2012), and undermines performance in experiments (Roskes et al. 2013).

When resources are depleted to a critical level, this potential threat to self-regulation is likely to impair employees' emotional well-being, resulting in persistent feelings of affective irritation. Coping with the affective irritation becomes an additional regulatory demand in and of itself, accelerating the subsequent decrease in resources. As a consequence, restrictions in processes of emotion regulation become more likely, for instance, in terms of unintended emotional spillover. In order to effectively regulate their emotions, employees try to actively prolong positive emotional states that arise from pleasant experiences to gain 
resources for subsequent work situations (positive affective spillover). On the other hand, people strive to cope with negative emotional experiences in such a way that subsequent work situations will not be affected by them (prevention of negative affective spillover; Williams \& Alligere 1994). However, as regulatory resources diminish, emotional regulation is likely to fail more often, resulting in less positive spillover and more negative spillover. These affective spillover effects are not limited to situations at work but may also impact the work-family interface with emotions spilling over from work to home (Ilies et al. 2009). Accordingly, emotion work is experienced by employees as emotionally exhausting (Brotheridge \& Grandey 2002) and may also result in health constraints (Zapf et al. 1999). In summary, time pressure should increase the likelihood of negative mood spillover and decrease the likelihood of positive mood spillover in emotion work. The relation between time pressure and emotional spillover can be attributed to feelings of affective irritation that result from the process of ego depletion.

Hypothesis 1: Time pressure will be (a) negatively related to the spilling over of positive mood and (b) positively related to the spilling over of negative mood.

Hypothesis 2: Affective irritation will mediate (a) the negative relation between time pressure and the spilling over of positive mood and (b) the positive relation between time pressure and the spilling over of negative mood.

\subsection{Restoring resources: Breaks may buffer the negative effects of high job demands during the work day}

Fortunately, ongoing regulatory activities do not always result in the collapse of selfregulation during work because in most cases, resources can be restored before they descend to a critical level. If employees are given the opportunity to effectively replenish their resources, physical health, psychological well-being, and work results may be maintained at a high level (De Jonge et al. 2012). Resource reactivation can be achieved through recovery, which takes place when job demands no longer challenge an employee's regulatory resources, typically during off time (Meijman \& Mulder, 1998). A considerable amount of research has demonstrated that various kinds of off-job recovery, such as end-of-day breaks (Sonnentag \& Zijlstra, 2006), weekends (Fritz \& Sonnentag 2005), and vacations (Fritz \& Sonnentag 2006) can help to effectively restore resources from one day to another.

Yet, employees in high-strain jobs, for instance, service workers engaging in emotional labour, will regularly be confronted with the need to replenish their regulatory resources before the work day is over. Only recently has research also begun to investigate the potential benefits of within-workday recovery, which may arise in particular during work breaks (Trougakos \& Hideg 2009). Breaks offer workers the opportunity to recover some of the resources that become depleted during exhausting working hours, and in the case of short and informal breaks (e.g., going to the rest room, chatting with colleagues, smoking), to immediately do so at times when resources have fallen to a critical level. Breaks may therefore be regarded as the main source of recovery and means for recovering resources during the work day, preventing slips and lapses, affective irritation, and other negative consequences of exhaustion on self-regulation in day-to-day work life, hence enabling employees to maintain their working capacity until closing time even under high pressure and demanding working conditions (Trougakos \& Hideg, 2009).

However, any beneficial effects of recovery periods on regulatory resources are likely to occur only when employees are able to psychologically detach; that is, regulatory resources can be reactivated only if employees can disrupt the work-related need for ongoing selfregulation by mentally distancing themselves from work and its related demands (Sonnentag 
\& Bayer 2005). Accordingly, recovery and resource restoration do not take place when individuals are occupied with work-related thoughts, tasks, or emotions even though they may be away from work, as in the case of unfinished tasks (Syrek \& Antoni 2014). Due to the limited amount of time and the proximity to the workplace (compared with off-work activities and rest), psychological detachment during breaks may be even harder to achieve and more crucial for effectively restoring resources. Consequently, Trougakos and Hideg (2009) claim that the recovery effect of breaks will mainly depend on the kinds of activities employees engage in during breaks.

\subsection{The essential ingredient is humour: Unpleasant breaks do not buffer}

In order to recover from work and to restore regulatory resources during their breaks, employees have to adopt detachment strategies that effectively interrupt the influence of job demands for the duration of the break. This suspensive effect of breaks may, on the one hand, be achieved by low effort activities (e.g., taking a nap or applying a relaxation technique) that relieve the demands and strain associated with work, thereby enabling people to restore their depleted resources. For instance, Krajewski et al. (2010) showed that post-lunchtime and afternoon strain could be effectively reduced through progressive muscle relaxation during lunch breaks, whereas small talk breaks with colleagues did not significantly reduce strain. On the other hand, effective recovery during breaks may also be achieved by engaging in preferred activities, restoring depleted resources through the positive feelings and subjective well-being that arise from the opportunity to deal with contents and activities one is interested in and enjoys engaging in. Accordingly, Trougakos et al. (2014) demonstrated that the recovery effect of social and work-break activities was moderated by the degree of autonomous choice: end-of-day fatigue was effectively reduced only when employees were free to choose their lunch-time activity. Resource replenishment may therefore be achieved through preferred activities that are perceived as pleasurable and enjoyable.

Furthermore, a break activity has to correspond with the type of regulatory demand in order for workers to achieve psychological detachment and restore depleted resources. More precisely, job demands, resources, and outcomes can be differentiated into physical, emotional, and cognitive types, and they need to correspond in order to produce optimal results (De Jonge \& Dormann, 2006). For instance, if an employee is confronted with emotional work demands (e.g., an annoying customer), dealing with this situation will essentially consume emotional resources (e.g., to enable the worker to stay calm and friendly despite being confronted with insults or abuse). Although physical activities or cognitive distraction might help the employee to detach afterwards, emotional support and encouragement will provide the most effective ways to restore his or her emotional resources. Thus, in order to effectively recover from emotion work, break activities need to include enjoyable activities that allow for emotional detachment (De Jonge et al. 2012). Put simply, employees need to share their break time with others who are in a positive, humorous mood.

According to Martin (2007: 5), humour "refers to anything that people say or do that is perceived as funny and tends to make others laugh", including mental processes and affective responses. As such, Romero and Cruthirds (2006: 59) define humour as "amusing communications that produce positive emotions and cognitions in the individual, group or organisation". Thus, laughing is a response to the perception of humour.

Humour is also described as the pleasurable emotion of mirth (Martin 2007), which may be accompanied by laughter. According to arousal theory, humour and laughter represent an interaction between a cognitive appraisal and physiological arousal (Banas et al. 2011; Martin 2007). The coping functions of humour are based on the tension-relief element of arousal. Humour helps a person to achieve distance from a problem, and this makes it easier 
to manage negative emotions such as anxiety and to cope effectively. Also, humour functions as a social lubricant (Martineau 1972), thus fostering closeness to other people and increasing social support.

Humour is negatively related to depression (Porterfield 1987) and negative affect (Newman \& Stone 1996). Furthermore, employee humour is associated with enhanced work performance, satisfaction, workgroup cohesion, health, and coping effectiveness, as well as decreased burnout, stress and work withdrawal (see the meta-analysis by Mesmer-Magnus et al. 2012). Humour has been identified as a moderator of the relation between stressors and mood (Martin \& Lefcourt, 1983; Nezu et al. 1988), although this view has been challenged (Porterfield 1987). For instance, coping humour buffered the detrimental effects of traumatic firefighting experiences on posttraumatic stress disorder and burnout (Sliter et al. 2014). Similarly, laughter was found to be negatively related to depression (Navarro et al. 2014) and to buffer the link between stressful life events and negative affect (Kuiper \& Martin 1998). Two studies reported a stress-relieving function of laughter in male samples (Berk et al. 2001; Bizi et al. 1988). Given the moderating function of psychosocial resources (i.e., social support and self-esteem) for the link between daily stress and mood disturbance (DeLongis $e t$ al. 1988), spending work breaks with colleagues should function as a social resource and should be beneficial to mental well-being. Furthermore, laughter was found to reduce psychological stress measures (White \& Winzelberg 1992), and affiliating with colleagues and joint laughter were found to strengthen the bond between employees, or in other words, positive humour was found to be related to team cohesion (Mesmer-Magnus et al. 2012). Thus, close relationships with colleagues are sources of social support that may help workers cope with high job demands. Time pressure should therefore be less associated with affective irritation when laughing with colleagues during breaks is prevalent.

Hypothesis 3: The frequency of laughing with colleagues during breaks will moderate the positive relation between time pressure and affective irritation such that a higher frequency of laughter will weaken the relation.

\section{Method}

\subsection{Participants and procedure}

This cross-sectional, quantitative study was conducted at four German retail stores. Complete surveys of 170 employees were obtained (70.8\% response rate). Paper and pen surveys were administered personally to employees, completed during work time, and immediately collected. Anonymity and confidentiality were guaranteed.

Of the participants, 56 were female $(32.9 \%), 106$ were male $(62.4 \%), 120$ worked fulltime (70.6\%), 26 part-time $(15.3 \%), 11$ were temporary staff $(6.5 \%)$, and 13 were trainees (7.6\%). Most of the participants were between 21 and $30(n=68,40 \%)$ or 31 and 40 years of age $(\mathrm{n}=56,32.9 \%)$, nine were between 16 and $20(5.3 \%), 26$ were between 41 and 51 $(15.3 \%)$, seven were between 51 and $60(4.1 \%)$, and four were older than $60(2.4 \%)$. Participants had worked for an average of 6.4 years $(\mathrm{SD}=5.3)$ at their actual workplace.

\subsection{Measures}

Time pressure. The independent variable was measured with the four-item time pressure subscale from the Instrument for Stress-Oriented Analysis of Work (ISTA; Semmer et al. 1999) on a 5-point Likert scale. Two questions (e.g., "How often are you pressed for time?") were rated as 1 (very rarely/never), 2 (rarely/approximately once a week), 3 
(occasionally/approximately once a day), 4 (frequently/several times a day), or 5 (very often/almost continuously). However, the answer choices differed for two questions: The question "How often do you have to delay or cancel your break due to too much work?" were rated as 2 (rarely/approximately once a month), 3 (occasionally/approximately once a week), 4 (frequently/several times a week), or 5 (very often/daily). The question "How often do you have to leave work later than planned due to too much work?" differed from the previous question in the anchors for the ratings of 3 (occasionally/several times a month) and 5 (very often/almost daily). Cronbach's alpha was .71.

Laughing during breaks. The moderator was assessed with the question "How often do you laugh with your colleagues during breaks?" The answer format consisted of 1 (very rarely/never), 2 (rarely/a few times per month), 3 (occasionally/several times a week), 4 (frequently/daily), and 5 (very often/several times a day).

Affective irritation. The mediator was measured with the Irritation Scale by Mohr et al. (2006). Five items captured affective irritation (e.g., nervousness), a sample item being "I get grumpy when others approach me." Participants were asked to rate each item on a 7-point Likert scale ranging from 1 (not at all) to 7 (completely). Cronbach's alpha was good ( $\alpha=$ $.85)$.

Mood spillover. Two questions covered the spilling over of positive and negative moods from break to work. Participants were asked to answer "How often does your positive mood transfer from your break to your subsequent work?" and "How often does your negative mood transfer from your break to your subsequent work?" on a 5-point Likert scale (see Laughing during breaks for categories).

Control variables. Sex and tenure in the organization were included because humour has been found to differ between sexes (e.g., Martin et al. 2003), and relationships with colleagues evolve over time (e.g., Jones 1986), likely resulting in changes in break behaviour with ongoing socialisation. Sex was assessed dichotomously $(1=$ female; $2=$ male $)$, and tenure in the actual workplace was measured continuously (years).

\subsection{Analyses}

We used the regression-based path analysis provided by the PROCESS software for SPSS (Hayes 2015). This software uses OLS regression, applies bootstrapped confidence intervals (CI), and generates conditional indirect effects in moderated mediation models (Preacher et al. 2007).

\section{Results}

Descriptive statistics and zero-order correlations for all variables are displayed in Table 1. Employees stated that they laugh often (i.e., daily) with their colleagues during breaks $(M=$ 3.91, $S D=0.99$ ). 
Table 1. Descriptive Statistics and Correlations between all Variables

\begin{tabular}{|c|c|c|c|c|c|c|c|}
\hline & $M(S D)$ & 1 & 2 & 3 & 4 & 5 & 6 \\
\hline $1 \mathrm{Sex}$ & - & & & & & & \\
\hline 2 Tenure & $6.4(5.3)$ & .05 & & & & & \\
\hline 3 Time pressure & $3.23(.75)$ & $.22^{* *}$ & .04 & $(.71)$ & & & \\
\hline $\begin{array}{l}4 \text { Laughing with colleagues } \\
\text { during breaks }\end{array}$ & $3.91(.99)$ & -.03 & -.00 & -.02 & & & \\
\hline 5 Affective irritation & $2.55(1.19)$ & .01 & $.20^{* *}$ & $.25^{* *}$ & $-.28^{* *}$ & $(.85)$ & \\
\hline 6 Positive mood spillover ${ }^{a}$ & $3.48(.97)$ & .02 & .02 & -.03 & $.63^{* *}$ & $-.20^{* *}$ & \\
\hline 7 Negative mood spillover ${ }^{a}$ & $1.85(.85)$ & .07 & -.10 & $.29^{* *}$ & -.06 & $.28^{* *}$ & -.05 \\
\hline
\end{tabular}

Note: $N=161-170$. Pearson correlations, two-sided. Reliabilities (Cronbach's $\alpha$ ) are on the

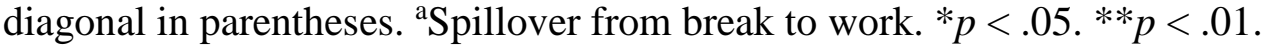

To test our hypotheses, we estimated a moderated mediation model (Model 7; Hayes 2015) using 1,000 bootstrap samples and 95\% bias-corrected bootstrap CIs for all indirect effects. Hypotheses 1 and 2 were partly supported by the results (Figure 1).

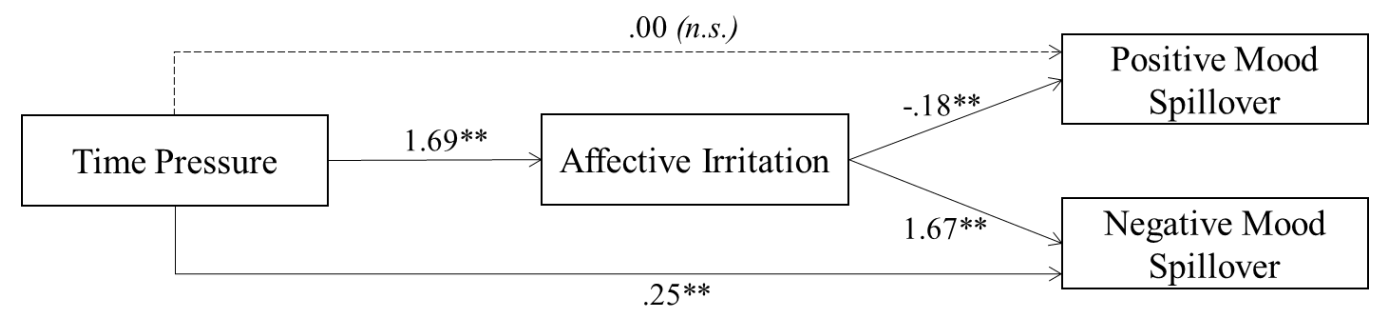

Figure 1. Association between time pressure, affective irritation and mood spillover according to regression-based path analysis $(* * p<.01)$

Time pressure was associated with emotional spillover (Hypothesis 1) with affective irritation mediating the relation between time pressure and the spilling over of positive mood from break to work (Hypothesis 2a; Table 2) and the relation between time pressure and the breakto-work spillover of negative mood (Hypothesis 2b; Table 3). Time pressure was significantly positively related to affective irritation $(B=1.69, S E=0.51, p \leq .001$; Tables 2 and 3), and affective irritation was negatively related to positive spillover $(B=-0.18, S E=$ $0.07, p \leq .01$; Table 2$)$ and positively related to negative spillover $(B=1.67, S E=0.57, p \leq$ .01 ; Table 3 ). Whereas time pressure was directly related to negative mood spillover (direct effect $=.25, p \leq .01,95 \%$ CI $[.072, .432]$, Table 3 ), it was not related to positive mood spillover (direct effect $=.00$, ns, 95\% CI $[-.215, .215]$, Table 2). Thus, the mediation of affective irritation was an indirect effect for the link between time pressure and the spilling over of positive mood. 
Table 2. Results of Moderated Mediation: Affective Irritation Mediates Time Pressure Positive Mood Spillover from Break to Work (Hypotheses 1a and 2)

\begin{tabular}{lllll}
\hline Predictor variable & $B$ & $S E$ & $t$ & $p$ \\
\hline DV: Affective irritation (mediator variable & & & & \\
model): $R^{2}=.23, p<.001$ & & & & \\
Constant & -1.49 & 1.68 & -.89 & .376 \\
Time pressure & 1.69 & 0.51 & 3.29 & .001 \\
Break laughter & 0.66 & 0.41 & 1.61 & .110 \\
Time Pressure x Break Laughter & -0.31 & 0.12 & -2.49 & .014 \\
\hline Sex & -0.20 & 0.18 & -1.11 & .270 \\
Tenure & 0.03 & 0.02 & 1.66 & .099 \\
\hline DV: Positive mood spillover: $R^{2}=.05, p=$ & & & \\
.117 & & & & \\
Constant & 3.79 & 0.40 & 9.43 & .000 \\
Affective irritation & -0.18 & 0.07 & -2.60 & .010 \\
Time pressure & 0.00 & 0.11 & 0.00 & .998 \\
\hline Sex & 0.05 & 0.16 & 0.30 & .762 \\
Tenure & 0.01 & 0.02 & 0.64 & .520 \\
\hline Break laughter & Unstandardised & Boot & Boot & Boot \\
& Boot indirect effects & $S E$ & LLCI & ULCI \\
\hline Conditional indirect effect of break laughter & & & & \\
$M-1 S D(2.91)$ & -0.14 & 0.07 & -.287 & -.013 \\
$M(3.90)$ & -0.09 & 0.05 & -.182 & -.007 \\
$M+1 S D(4.89)$ & -0.03 & 0.03 & -.115 & .011 \\
\hline & Unstandardized boot & Boot & Boot & Boot \\
Index of moderated mediation (by irritation) & value & $S E$ & LLCI & ULCI \\
\hline Not Listwise $N=161$. LL $=$ & .032 & .005 & .128 \\
\hline
\end{tabular}

Note: Listwise $N=161$. LL $=$ lower limit. $\mathrm{CI}=$ confidence interval. $\mathrm{UP}=$ upper limit. Bootstrap sample size $=1,000 . \mathrm{CI}=95 \%$.

The results also supported Hypothesis 3 such that the frequency of laughing with colleagues during breaks moderated the relation between time pressure and affective irritation (interaction $\mathrm{B}=-0.31, p \leq .05$; Tables 2 and 3 ). More precisely, the positive association of time pressure with affective irritation was weaker when joint laughter during breaks was more frequent (Figure 2). When the frequency of laughter with colleagues during breaks was high (i.e., $M+1 S D$ ), time pressure was no longer significantly associated with affective irritation (indirect effect $=-0.03, S E=0.03,95 \%$ CI $[-.115, .011]$, Table 2; indirect effect $=$ $0.03, S E=0.03,95 \%$ CI $[-.009, .097]$, Table 3). 


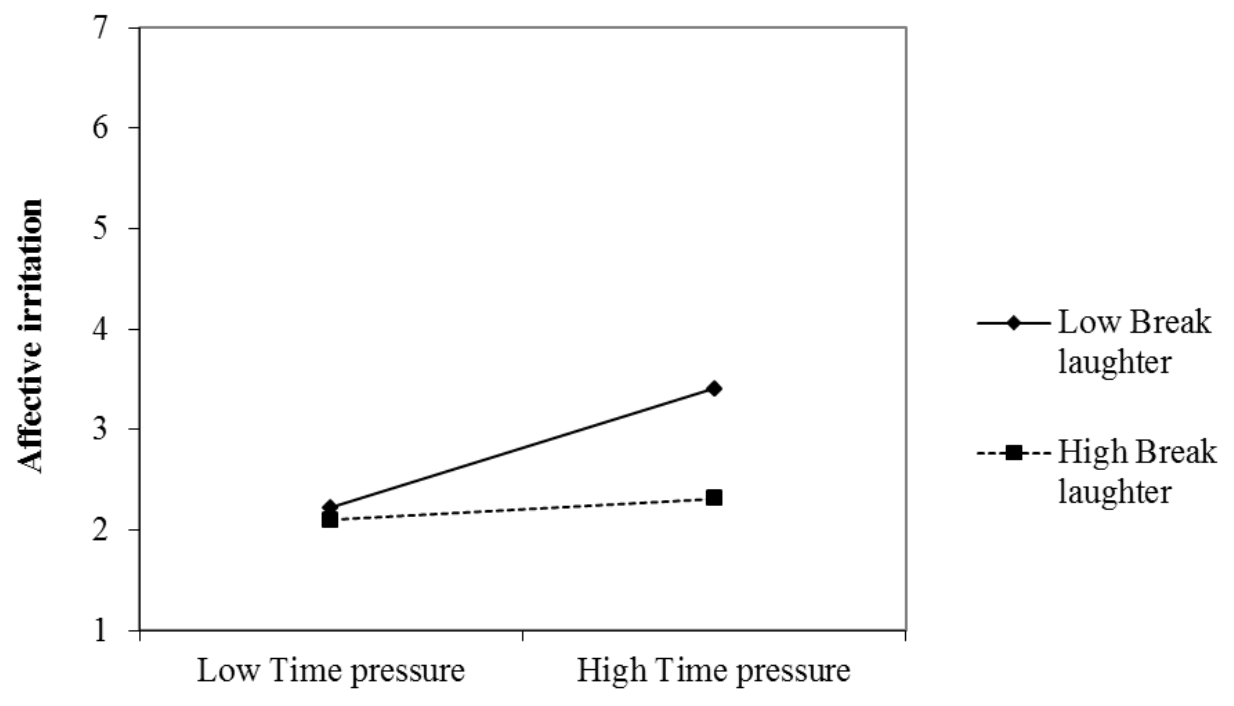

Figure 2. Moderation of the positive association between time pressure and affective irritation by frequency of laughter with colleagues during breaks (Low $M-1 S D$, High $M+1 S D)$.

Table 3. Results of Moderated Mediation: Affective Irritation Mediates Time Pressure Negative Mood Spillover from Break to Work (Hypothesis 1b and 2)

\begin{tabular}{lllll}
\hline Predictor variable & $B$ & $S E$ & $t$ & $p$ \\
\hline DV: Affective irritation (mediator variable & & & & \\
model): $R^{2}=.23, p<.001$ & & & & \\
Constant & -1.49 & 1.68 & -.89 & .376 \\
Time pressure & 1.69 & 0.51 & 3.29 & .001 \\
Break laughter & 0.66 & 0.41 & 1.61 & .110 \\
Time Pressure x Break Laughter & -0.31 & 0.12 & -2.49 & .014 \\
\hline Sex & -0.20 & 0.18 & -1.11 & .270 \\
Tenure & 0.03 & 0.02 & 1.66 & .099 \\
\hline DV: Negative mood spillover: $R^{2}=.14, p<.001$ & & & & \\
Constant & 0.72 & 0.34 & 2.13 & .035 \\
Affective irritation & 1.67 & 0.57 & 2.89 & .004 \\
Time pressure & 0.25 & 0.09 & 2.76 & .007 \\
\hline Sex & 0.04 & 0.14 & 0.30 & .764 \\
Tenure & -0.02 & 0.01 & -2.02 & .045 \\
\hline Break laughter & Unstandardized & Boot & Boot & Boot \\
& Boot indirect & $S E$ & LLCI & ULCI \\
& effects & & & \\
\hline Conditional indirect effect of break laughter & & & & \\
$M-1 S D(2.91)$ & 0.13 & 0.06 & .035 & .286 \\
$M(3.90)$ & 0.08 & 0.04 & .020 & .170 \\
$M+1 S D(4.89)$ & 0.03 & 0.03 & -.009 & .097 \\
\hline & Unstandardized & Boot & Boot & Boot \\
Index of moderated mediation (by irritation) & boot value & $S E$ & LLCI & ULCI \\
\hline & -0.051 & .031 & -.141 & -.008 \\
\hline
\end{tabular}


Note: Listwise $N=161$. LL $=$ lower limit. $\mathrm{CI}=$ confidence interval. $\mathrm{UP}=$ upper limit. Bootstrap sample size $=1,000 . \mathrm{CI}=95 \%$.

Overall, the CI did not include zero for the index of moderated mediation for the spilling over of positive mood (index $=0.055, S E=0.03,95 \%$ CI $[.005, .128]$, Table 2) or for the spilling over of negative mood (index $=-0.051, S E=0.03,95 \%$ CI [-.141, -.008], Table 3).

\section{Discussion}

Our results highlight the importance of activity type for within-workday recovery and thus, for counteracting ego depletion. Socialising with colleagues during work breaks, accompanied by laughter, is related to higher emotional well-being, more of the subsequent transfer of positive mood, and less of the transfer of negative mood from break to work. In this way, post-break emotional labour and thereby service may profit from replenished resources.

For employees reporting frequent laughter with colleagues during breaks (i.e., several times a day), time pressure was not significantly associated with affective irritation. This suggests a moderator effect in the sense of the coping function of humour (e.g., Martin \& Lefcourt 1983; Navarro et al. 2014). Laughing with colleagues may strengthen social bonds and thus satisfy the need for relatedness. Results also indicate that humour enables effective psychological detachment during breaks: laughter with colleagues replenishes the emotional resources that are depleted by the emotional demands of service work.

Time pressure was reported as moderate on average but was still experienced daily or at least several times a week (break delay) or several times a month (late quitting time) by the respondents. The strain in our retail sample might therefore be due to the combination of time pressure and emotional demands (of emotional labour) than by the pure quantity of work. Affective irritation was also rather low (a little on average). The moderating effect of laughing with colleagues might therefore be more pronounced in samples with higher levels of strain. In line with the low irritation, the spilling over of positive mood was rated as more likely (several times a week to daily) than the spilling over of negative mood (a few times per month).

Time pressure is per se problematic for the organising of individual breaks. Posthoc analyses of additional control variables revealed that, in our sample, time pressure was significantly negatively related to spending breaks in the provided rooms, and this was consequently related to spending breaks with colleagues. Spending breaks with colleagues was significantly positively related to laughing with colleagues, but only the latter was negatively related to affective irritation. Thus, as we expected from theory, solely socialising during breaks does not buffer ego depletion. Instead, social breaks have to be enjoyable, operationalised by shared laughter in our study, in order to effectively restore resources and prevent problems with self-regulation.

\subsection{Strengths, limitations, and future research}

Including nearly three quarters of the entire staff of four retail stores, our sample is likely to reliably represent the target population of service workers. However, the design of our study was only cross-sectional, and hence, causal inferences cannot be drawn. Future research should therefore adopt a longitudinal design, and given the focus on state variables such as mood, a diary study is recommended.

All variables were assessed via self-report, raising the problem of common-method bias. However, by definition, ego depletion and psychological detachment refer to subjective 
states. Also, self-reports are not inherently flawed (Chan 2009) and other-ratings are not per se more reliable as such methods are usually correlated (Lance \& Siminovsky 2014). Our moderator (laughter during breaks) as well as our outcomes (mood spillover) were based on single-item measures. Whereas the concept of the moderator appeared to be adequately captured with one straightforward question, future studies should introduce and evaluate more reliable scales for measuring mood spillover from break to work. The actual differences between mood during breaks and mood at work should be captured in future diary studies. Also, findings should be replicated in samples under (quantitatively) higher strain as well as in more diverse samples of employees from different industries and work demands in order to reinforce the generalisability of our results.

We did not assess whether employees spent their breaks with colleagues voluntarily, and this may be an important precondition for recovery effects (Trougakos et al. 2014). However, breaks were given on a fixed schedule at the four retail stores, and employees were free to choose where and with whom to spend their breaks. Due to the nature of the work (service with customers), the obligatory physical absence from the workplace during breaks prevented employees from conducting any work activities during their breaks. Hence, we assumed that employees in our sample had a great deal of autonomy over how to spend their breaks. The kind of humour shared with colleagues, that is, the cause for laughter, may have an impact too. Humour at the expense of others (i.e., aggressive humour) creates social distance (e.g., Holmes \& Marra, 2002) and is often used to highlight power or status differences. However, asking whether employees laugh together with colleagues implies a rather affiliative style. Whereas the effects of laughter with colleagues (or even with customers) during work may be similar to the effects of laughter during breaks, detachment should be higher and emotional resources are more likely to be replenished during breaks.

Our results may be applied to other high-strain jobs including emotional labour especially within the retail sector. Effects of laughter with colleagues during breaks might be even more pronounced in jobs with frequently interrupted breaks (e.g., nursing) or jobs where shift work or virtual cooperation prevents employees from gathering with colleagues. Future research may also examine whether and how our results can be transferred to virtual teams. Would socialising during lunch breaks in front of a screen be an enjoyable and effective alternative to being physically present with colleagues?

\subsection{Implications for practice}

Employers need to reliably schedule breaks and to facilitate the adherence to breaks. The break schedule should also make it possible to socialise with colleagues. On the one hand, this requires an adequate space where it is comfortable to spend time. On the other hand, employers need to encourage employees to actually take their breaks. Especially during times characterised by a high work load (e.g., the Christmas season in retail), employees' recovery during breaks is especially warranted. Thus, it is most important for employers to act counterintuitively and to explicitly encourage employees to take and enjoy their breaks during such times when skipping or shortening breaks is more likely to occur. The general acceleration of life and the intensification of job demands (e.g., multitasking) may change employers' attitudes toward breaks, making them want to shorten or eliminate breaks in order to increase efficiency. However, our results highlight the necessity of enjoyable breaks for replenishing employees' resources. Thus, even time pressure must not be a reason to shorten or abolish breaks. Our findings may also shed light on informal breaks, which employers often view critically. Though we did not explicitly ask for formal breaks but rather asked for "taken" breaks, in the light of our findings, informal breaks may represent workers' active attempts to replenish resources. In the stores that formed our sample, smokers were often 
accompanied by nonsmokers when taking cigarette breaks. However, excessive informal breaks may jeopardise performance, and the role of informal or self-chosen work breaks (e.g., coffee breaks) need to be examined with regard to ego depletion.

Emotional resources are necessary for countering emotional demands, making emotional detachment necessary for an effective recovery. Also, physical demands are aligned with physical detachment for recovery, and cognitive detachment may even be detrimental to cognitive work performance (De Jonge et al. 2012). Our findings may be especially relevant for high-strain jobs, that is, emotionally demanding work. Whereas the quality of the break is important in terms of the type of activity, recovery may be jeopardised if social activities during lunch breaks are not voluntary (Trougakos et al. 2014). As a lack of autonomy with respect to break activities may cause further resource depletion, breaks should be regularly spent with colleagues on a voluntary basis only. In addition, space for individual retreat should be provided. Employees should strive to engage in laughter with their colleagues more than once a day. Especially employees in emotionally demanding service jobs may benefit from replenishing their (emotional) resources. Actively focusing on humour interventions might not be necessary, but organizational culture and leadership styles pave the way for good work relationships. If a team climate is pleasant, the likelihood that employees will want to share their breaks with colleagues will be higher. Once employees gather, humour will take care of itself.

\section{References}

Banas, J. A., Dunbar, N., Rodriguez D. \& Liu. S.- J. (2011). 'A review of humor in educational settings: Four decades of research'. Communication Education 60, pp. 115144. doi:10.1080/03634523.2010.496867.

Berk, L. S., Felten D. L., Tan S. A., Bittman B. B. \& Westengard J. (2001). 'Modulation of neuroimmune parameters during the eustress of humor-associated mirthful laughter'. Alternative Therapies in Health and Medicine 7 (2), pp. 62-76.

Bizi, S., Keinan G. \& Beit-Hallahmi B. (1988). 'Humor and coping with stress: A test under real-life conditions'. Personality and Individual Differences 9 (6), pp. 951-956.

Brotheridge, C. M., \& Grandey, A. A. (2002). 'Emotional labor and burnout: Comparing two perspectives of "people work". Journal of Vocational Behavior 60, pp. 17-39. doi:10.1006/jvbe.2001.1815.

Chan, D. (2009). 'So why ask me? Are self-report data really that bad?', in Lance, C. E. \& Vandenberg, R. J. (eds.), Statistical and Methodological Myths and Urban Legends, New York: Routledge, pp. 309-336.

De Jonge, J. \& Dormann, C. (2006). 'Stressors, resources and strains at work: A longitudinal test of the Triple Match Principle'. Journal of Applied Psychology 91 (6), pp. 1359-1374.

De Jonge, J., Spoor, E., Sonnentag, S., Dormann, C. \& van den Tooren, M. (2012). "“Take a break?!"Off-job recovery, job demands, and job resources as predictors of health, active learning, and creativity'. European Journal of Work and Organizational Psychology 21, pp. 321-348. doi:10.1080/1359432X.2011.576009

DeLongis, A., Folkman, S. \& Lazarus, R. S. (1988). 'The impact of daily stress on health and mood: Psychological and social resources as mediators'. Journal of Personality and Social Psychology 54 (3), pp. 486-495.

Fritz, C. \& Sonnentag, S. (2005). 'Recovery, health, and job performance: Effects of weekend experiences'. Journal of Occupational Health Psychology 10 (3), pp. 187-199. 
Fritz, C. \& Sonnentag, S. (2006). 'Recovery, well-being, and performance-related outcomes: The role of work load and vacation experiences'. Journal of Applied Psychology 91 (4), pp. 936-945.

Hayes, A. F. (2015). 'The PROCESS makro for SPSS and SAS'. Available online: http://www.processmacro.org/download.html [Accessed on 26 January 2015].

Hochschild, A.R. (1979). 'Emotion work, feeling rules, and social structure'. American Journal of Sociology 85 (3), pp. 551-575.

Holmes, J. \& Marra, M. (2002). 'Having a laugh at work: How humour contributes to workplace culture'. Journal of Pragmatics, 34, 1683-1710.

Ilies, R., Wilson, K. S. \& Wagner, D. T. (2009). 'The spillover of daily job satisfaction onto employees' family lives: The facilitating role of work-family integration'. Academy of Management Journal 52 (1), pp. 87-102.

Jones, G. R. (1986). 'Socialization tactics, self-efficacy, and newcomers' adjustments to organizations'. The Academy of Management Journal 29 (2), pp. 262-279.

Kleiner, S. (2014). 'Subjective time pressure: General or domain specific?'. Social Science Research 47, pp. 108-120. doi:10.1016/j.ssresearch.2014.03.013

Krajewski, J., Wieland, R. \& Sauerland, M. (2010). 'Regulating strain states by using the recovery potential of lunch breaks'. Journal of Occupational Health Psychology, 15, pp. 131-139. doi:10.1037/a0018830

Kühnel, J., Sonnentag, S. \& Bledow, R. (2012). 'Resources and time pressure as day-level antecedents of work engagement: Day-level JD-R model'. Journal of Occupational and Organizational Psychology 85, pp. 181-198. doi:10.1111/j.2044-8325.2011.02022.x

Kuiper, N. A., \& Martin, R. A. (1998). 'Laughter and stress in daily life: Relation to positive and negative affect'. Motivation and Emotion 22 (2), pp. 133-153.

Lance, C. E. \& Siminovsky, A. B. (2014). 'Use of "independent" measures does not solve the shared method bias problem', in Lance, C. E. \& Vandenberg, R. J. (eds.), More Statistical and Methodological Myths and Urban Legends, New York: Routledge, pp. 276-291.

Martin, R. A. (2007). The Psychology of Humor: An Integrative Approach. Burlington, MA: Elsevier.

Martin, R. A., Kuiper, N. A., Olinger, L. J. \& Dance, K. A. (1993). 'Humor, coping with stress, self-concept, and psychological well-being'. Humor: International Journal of Humor Research 6 (1), pp. 89-104.

Martin, R. A. \& Lefcourt, H. M. (1983). 'Sense of humor as a moderator of the relation between stressors and moods'. Journal of Personality and Social Psychology 45 (6), pp. 1313-1324.

Martin, R. A., Puhlik-Doris, P., Larsen, G., Gray, J. \& Weir, K. (2003). 'Individual differences in uses of humor and their relation to psychological well-being: Development of the Humor Styles Questionnaire'. Journal of Research in Personality 37(1), pp. 4875.

Martineau, W. H. (1972). 'A model of the social functions of humor'. in Goldstein, J. \& McGhee, P. E. (eds.), The Psychology of Humor, New York: Academic Press, pp. 101125.

Meijman, T. F. \& Mulder, G. (1998). 'Psychological aspects of workload', in Drenth, P. J. D., Thierry, H. \& de Wolff, C. J. (eds.), Handbook of Work and Organizational Psychology (Volume 2: Work Psychology), Hove, UK: Psychology Press, pp. 5-33.

Mesmer-Magnus, J., Glew, D. J. \& Viswesvaran, C. (2012). 'A meta-analysis of positive humor in the workplace'. Journal of Managerial Psychology 27, pp. 155-190. doi:10.1108/02683941211199554 
Mohr, G., Müller, A., Rigotti, T., Aycan, Z. \& Tschan, F. (2006). 'The assessment of psychological strain in work contexts'. European Journal of Psychological Assessment 22, pp. 198-206. doi:10.1027/1015-5759.22.3.198

Muraven, M. \& Baumeister, R. F. (2000). 'Self-regulation and depletion of limited resources: Does self-control resemble a muscle?'. Psychological Bulletin 126 (2), pp. 247.

Navarro, J., del Moral, R., Alonso, M. F., Loste, P., Garcia-Campayo, J., Lahoz-Beltra, R. \& Marijuán, P. C. (2014). 'Validation of laughter for diagnosis and evaluation of depression'. Journal of Affective Disorders 160, pp. 43-49. doi:10.1016/j.jad.2014.02.035

Newman, M. G. \& Stone, A. A. (1996). 'Does humor moderate the effects of experimentallyinduced stress?' Annals of Behavioral Medicine 18 (2), pp. 101-109.

Nezu, A. M., Nezu, C. M. \& Blissett, S. E. (1988). 'Sense of humor as a moderator of the relation between stressful events and psychological distress: A prospective analysis'. Journal of Personality and Social Psychology 54 (3), pp. 520-525

Porterfield, A. L. (1987). 'Does sense of humor moderate the impact of life stress on psychological and physical well-being?'. Journal of Research in Personality 21 (3), pp. 306317.

Preacher, K. J., Rucker, D. D. \& Hayes, A. F. (2007). 'Assessing moderated mediation hypotheses: Theory, method, and prescriptions'. Multivariate Behavioral Research 42, pp. 185-227.

Robert, C. \& Wilbanks, J. E. (2012). 'The Wheel Model of humor: Humor events and affect in organizations'. Human Relations 65, pp. 1071-1099. doi:10.1177/0018726711433133

Romero, E. J. \& Cruthirds, K. W. (2006). 'The use of humor in the workplace'. The Academy of Management Perspectives 20 (2), pp. 58-69.

Roskes, M., Elliot, A. J., Nijstad, B. A. \& De Dreu, C. K. (2013). 'Time pressure undermines performance more under avoidance than approach motivation'. Personality and Social Psychology Bulletin 39 (6), pp. 803-813.

Semmer, N. K., Zapf, D. \& Dunckel, H. (1999). 'Instrument zur Stressbezogenen Tätigkeitsanalyse (ISTA) [Instrument for stress-related job analysis (ISTA)]', in Dunckel, H. (ed.), Handbuch psychologischer Arbeitsanalyseverfahren, Zürich: vdf Hochschulverlag, pp. 179-204.

Sliter, M., Kale, A. \& Yuan, Z. (2014). 'Is humor the best medicine? The buffering effect of coping humor on traumatic stressors in firefighters'. Journal of Organizational Behavior 35, pp. 257-272. doi:10.1002/job.1868

Sonnentag, S. \& Bayer, U.-V. (2005). 'Switching off mentally: Predictors and consequences of psychological detachment from work during off-job time'. Journal of Occupational Health Psychology 10 (4), pp. 393-414.

Sonnentag, S. \& Zijlstra, F. R. H. (2006). 'Job characteristics and off-job activities as predictors of need for recovery, well-being and fatigue'. Journal of Applied Psychology, 91 (2), pp. 330-350.

Syrek, C. J. \& Antoni, C. H. (2014). 'Unfinished tasks foster rumination and impair sleeping - Particularly if leaders have high performance expectations'. Journal of Occupational Health Psychology 19 (4), pp. 490-499.

Trougakos, J. P. \& Hideg, I. (2009). 'Momentary work recovery: The role of within-day work breaks' in Sonnentag, S., Perrewé, P. L. \& Ganster, D. C. (eds.), Current Perspectives on Job-Stress Recovery (Research in Occupational Stress and Well-Being, Volume 7), Bingley: Emerald Group Publishing, pp.37 - 84.

Trougakos, J. P., Hideg, I., Cheng, B. H. \& Beal, D. J. (2014). 'Lunch breaks unpacked: The role of autonomy as a moderator of recovery during lunch'. Academy of Management Journal 57, pp. 405-421. doi:10.5465/amj.2011.1072 
White, S. \& Winzelberg, A. (1992). 'Laughter and stress'. Humor 5 (4), pp. 343-355.

Williams, K. J., \& Alliger, G. M. (1994). 'Role stressors, mood spillover, and perceptions of work-family conflict in employed parents'. Academy of Management Journal 37, pp. 837-868. doi:10.2307/256602

Wood, R. E., Beckmann, N. \& Rossiter, J. R. (2011). 'Management humor: Asset or liability?' Organizational Psychology Review 1, pp. 316-338. doi:10.1177/2041386611418393

Zapf, D., Vogt, C., Seifert, C., Mertini, H. \& Isic, A. (1999). 'Emotion work as a source of stress: The concept and development of an instrument'. European Journal of Work and Organizational Psychology 8, pp. 371-400. doi:10.1080/135943299398230 